\title{
Simulation as a learning Approach and its Influence on Self-Efficacy and Intrinsic Motivation of Nursing Students
}

\author{
Abeer Abd El Fattah Abou Shosha \& Zizi Fikry Abd El Rassol. \\ Lecturer, Nursing Education Department, Faculty of Nursing, Damanhour University Egypt. \\ Lecturer, Medical Surgical Nursing Department, Faculty of Nursing, Damanhour University Egypt.
}

\begin{abstract}
Simulation provides a safe, non-threatening learning environment, which allows for the development of student self-efficacy and confidence when attempting skills in the actual clinical environment. Aim of the study: to assess the effect of simulation as a learning approach on self-efficacy and intrinsic motivation of the first year medical nursing student in Damanhour University (Egypt). Settings: Faculty of Nursing Damanhour University. Sampling all medical surgical nursing students enrolled at the first year, $(n=311)$ at the academic year 2014-2015. Tools: Two tools were used to collect data. Tool I: General Self-Efficacy Scale (GSE) Tool II: Intrinsic Motivation Inventory (IMI); as well as demographic characteristics. Results: Confidence level and intrinsic motivation increased significantly post - simulation intervention. A significant positive weak correlation between total self- efficacy and total intrinsic motivation. There is a statistical significant difference between self-efficacy and both gender and studying hours. Conclusion Simulation is an active learning strategy that can effectively be integrated into all levels of nursing education to foster student-centered instruction. Results of this study showed that there was a significant difference in the students' self - efficacy and intrinsic motivation after using simulation. Recommendation Educators should be encouraged to use the various forms of simulation when appropriate with nursing students.
\end{abstract}

\section{Key Words : Low-Fidelity Simulation, Simulation as a Teaching Strategy, Self- Efficacy Scale \& Intrinsic Motivation Inventory.}

\section{Introduction}

Despite the fact that academic institutions are faced with insufficient numbers of faculty, clinical settings and resources, nursing education has relied on clinical placements and real patients as the primary means by which clinical skills are taught (Cant \& Cooper, 2010). New strategies are being considered to educate student nurses to assume increasingly complex roles that require higher levels of critical thinking(Cant \& Cooper ,2010). The National League for Nursing (NLN) declared that nurse educators must provide learning environments that facilitate students' critical thinking, self-reflection and prepare graduates for practice in a complex, dynamic health care environment (NLN, 2010).

Nursing education has not only focus on didactical issues as what to do and why, but it also includes the knowledge of how to do it (Smith, 2009). Moreover, it includes both technical and non-technical skills based on scientific knowledge; as well as professional judgment in making professional practice fallible, which makes patient safety a fundamental principle of good patient care (World Health Organization (WHO) 2011).Teaching skills in the clinical settings may not always provide the best atmosphere for learning as faculty may not be proficient in the clinical skills, which can make the clinical experience less satisfying to the student (Wars-Smith 2008).The simulation experience allows the student to remediate and practice skills; therefore increasing self -efficacy, before entering the clinical setting, which in turn improve students' selfconfidence (Wars-Smith, 2008).

Simulation is viewed as "activities that mimic the reality of a clinical environment and are designed to demonstrate procedures, decision-making and critical thinking through techniques, such as : role playing and the use of devices, such as: interactive videos or mannequins" (Jeffries, 2005). It is an innovative teaching and learning tool that may fit into the rapidly changing world of nursing education (Smith \& Roehrs , 2009). Fidelity reflects the level of realism incorporated into the simulation; however, while fidelity simulation is non-immersive simulation , such as: a case study (patient scenario) with a medical history; current assessment data and clinical orders outlined on a computer program that offer students an opportunity to create care plans and utilize clinical decision-making; however no real clinical practice is experienced (Smith \& Roehrs , 2009). Even this may have some sense of patient's response; students are not able to interact with a realistic, life-like environment (Smith \& Roehrs, 2009). Low-fidelity simulation creates a semblance of reality by using static manikins with props and techniques, such as role playing, and are also, exhibited in the uncomplicated scenarios used with 
introductory nursing students; and in teaching and evaluating them (Jeffries, 2005). Rystedt \& Lindstrom (2001) argued that low-fidelity simulations may produce high-value principles because they focus on helping nursing students develop skills that are required to practice as safe and competent professionals upon graduation.

Simulation was proved to be an effective method for improving student self-efficacy and to help create a positive learning environment which contributes to self-confidence (Leigh, 2008). Perceived selfefficacy is viewed as: "people's beliefs about their capabilities to produce designated levels of performance that exercise influence over events that affect their lives"; it also determine how people feel, think, motivate themselves and behave (Bandura, 2006). Therefore, self-efficacy, is a base for selfconfidence, and is essential for nursing students' ability \& performance in the clinical settings ; despite that they often report lack of self-confidence and apprehension, when they are expected to meet performance criteria, which influence clinical decision-making. (Norman, 2012).

Self-confidence tends to be improved when the learning experience is simulation-based Yuan, Williams, Fang, \& Ye, (2012). Learner confidence in their knowledge is significantly improved after participation in the simulation program by using a pretest/posttest design (Foronda et al., 2013). Simulation offers several ways to enhance motivation at all levels; one area is through practice and the ability to achieve success or mastery through the support of teachers or facilitators (Paige, 2013). The active role of the learner plays in the learning process with simulation also contributes to motivation (Paige, 2013). Intrinsic motivation is the internal driver that pushes learners to accomplish goals and objectives; and it involves people doing an activity because they find it interesting and derive spontaneous satisfaction from the activity itself (Gagne \& Deci, 2005).

Furthermore, self-efficacy is an individual's belief in one's ability to succeed; while, motivation is "the manifestation of human tendency toward learning and creativity" (Bandura, 1977). The works of nursing students have shown that both concepts significantly impact achievement in the learning environment (Bandura, 1977). Bandura, (2006) pointed out that self-efficacy determines a person's level of motivation, and proposed that high feelings of selfefficacy causes one to set high personal goals and these challenging goals lead to higher levels of motivation and performance.

In Egypt, Soliman, Sheble, Shrief, (2014) studied the effectiveness of simulation training on clinical nursing education and competence on first year nursing students Faculty of Nursing Mansoura
University students; and they found that simulation was proved to be effective on students' performance. Furthermore, Mohsen, Okby, Reiad, Fareed, El Sheikh, (2011), reported that simulation allows critical thinking practice for wide range of conditions than one offered by traditional demonstration at ElMonfoia University.

However, there is no sufficient amount of evidences to ascertain the relationship between simulationbased learning and students' self-efficacy. This study adds new information to an existing knowledge - based regarding simulation and nursing education by investigating the value of simulation on the selfefficacy and intrinsic motivation of nursing students. More specifically, this study explores the effects of different forms of simulation on nursing students' self-efficacy and intrinsic motivation.

\section{Significance of the study}

The researchers faced a problem of the increased student numbers, shortage of the staff members and lack of hospital facilities to train first year students in the medical surgical department, at the faculty of nursing. So there was a need to find alternative way to solve this problem.

\section{Aim of the study}

To assess the effect of simulation as a learning approach on the medical surgical nursing students' self-efficacy and intrinsic motivation.

\section{Research hypothesis}

Students who were exposed to no fidelity and low fidelity simulation, exhibited higher self-efficacy and motivation.

\section{Subject \& Method}

\section{Materials}

Research design: Pre-experimental one group pretest/ post- test design.

Setting

The study was conducted at Faculty of Nursing Damanhour University (El - Beheira governorate); located inside Damanhour National Medical Institute. It is composed of three floors, and includes nine scientific nursing departments, namely: medical surgical, critical care, obstetrics and gynecology, community health, nursing administration, psychiatric and mental health, pediatrics, geriatrics and nursing education. Each department has different clinical areas, where nursing students practice. 


\section{Subjects}

-The study subjects included all nursing students who were enrolled, at the academic year (2014-2015), from the above mentioned setting, in medical surgical nursing course, at the first year the total $(n=311)$.

-At the beginning of the year, didactic traditional lectures were introduced to the students. The baseline data for the evaluation of knowledge of the students were obtained by pre-test (General Self - Efficacy Questionnaire).

\section{Tools of data collection}

Data were collected through self-administered questionnaires that were distributed among the four academic year nursing students. Starting from 9:00 Am, until 2:00 PM, time taken for each student was around 20 to 25 minutes. Data was collected in the period from $10 / 10 / 2014$ to $22 / 2 / 2015$ at the end of the $1^{\text {st }}$ semester of the academic year (2014-2015).

Two tools were used in this study

Tool (I) : General Self-Efficacy Scale (GSE) developed by Schwarzer \& Scholz (2000) it consists of 18 statements that was used to evaluate a general sense of perceived self-efficacy prior to simulation and after simulation and to assess sense of competence and effectiveness of simulation.. Each statement has five choices that describe a situation and allows the respondent to choose one response that they would take. Each action corresponds to one of the five choices measured on 5-point Likert scale ranging from (1) to (5).

Scoring: Not confident (score from 18; 27), Slight confident (score from 28: 45)

Moderately confident (score from 46:63), highly confident (score from 64:72) and the fifth very highly confident more than 72 .

Tool (II): Intrinsic Motivation Inventory (IMI) was developed by Ryan and his colleagues (1983), (Jeffries, 2007b). Post- simulation basic intrinsic motivation on the underlying sub-scales, which are ; interest-enjoyment (7- items); perceived competence (5- items); effort/-importance (5 -items) ; pressuretension (5 items); value-usefulness and relatedness (5 -items). The IMI is , a 34 -item measured on , 7 Likert scale, ranging from (1,2 not at all true ) (3,4 somewhat true) (5,6,7 very true). In addition to the ranked questions, three open-ended questions were present, which the participant is asked to answer what the activity is useful for, why the activity is important, and how the activity can help them. Scoring: Low: score $\%<50 \%$, Moderate: score $\% 50$ $\%-<75 \%$ and High: score $\% \geq 75 \%$.

In addition to the demographic characteristics of nursing students containing the gender, age and hours of studying at home.

\section{Methods}

- Administrative process

- Before the conduction of the study, official permission was obtained from Dean, faculty of nursing to secure approval of responsible authorities and for explanation of the purpose of the study.

- Tools Validity and reliability

- The two tools used in this study: General SelfEfficacy Scale (GSE) and Intrinsic Motivation Inventory (IMI) were tested for their reliability by measuring the internal consistency of items using Cronbach's alpha. The value of tool (I) was 0.81 and tool (II) was: 0.88. Face validity of the questionnaire was done.

- Pilot study

- Pilot study was carried out on 31 students, (10\%) who were not included in the study sample in order to ensure the clarity of the tools and its comprehension by the target population.

\section{- Data collection}

-Data were collected through self-administered questionnaires (tool I and tool II) that were distributed among the undergraduate medical surgical nursing students in first year at faculty of nursing Damanhour University during the first semester, of the academic year (2014-2015).

-Students were organized in groups four days in the week.

- Simulation introduced by the medical surgical staff members after training them, by the education staff members, using: role playing, demonstration and re-demonstration, case study, discussion. In addition to using educational materials used as: videos, with slide projector, posters; the selected content was organized in topics for better visualization.

-Introduce topics of medical - surgical nursing to the first year student (one topic/ week).

-Pre-test was performed to assess their self-efficacy by using General Self-Efficacy Scale (GSE) questionnaire.

-Introduce the simulations method of teaching, by dividing the first year nursing students into eight groups, four groups /day for four days, each group was composed of 19 to 20 students and one clinical instructor.

-No fidelity simulation was used: for example; applying role play, demonstration and redemonstration in bed making and vital signs lectures.

-Also, low fidelity simulation was used: as using IV arm (demo-arm contain veins) and IM leg (demoleg) for IV and IV injection lectures. 
-After intervention, a post-test was performed using the self -efficacy scale and intrinsic motivation inventory to assess the effectiveness of simulation.

\section{- Ethical considerations}

A written informed consent to participate in the study was obtained from the students. The questionnaire was accompanied with a letter explaining the purpose of research. Anonymity and confidentiality were considered.

\section{- Statistical analysis}

After data were collected it was revised, coded and fed to statistical software SPSS IBM version 20. The given graphs were constructed using Microsoft excel software. All statistical analysis was done using two tailed tests and alpha error of 0.05. All discrete scores for items concerning self- efficacy and motivation inventory were summed together and a Pearson with a score \% less than $50 \%$ were considered to have low level while those who have a score $\%$ ranged from $50-74.9 \%$ were considered to have a moderate level and others $75 \%$ and more was considered to have high levels.

\section{The following statistical tests were used}

Descriptive statistics in the form of frequencies and percent were used to describe the categorical data variables while scale data were expressed by mean and standard deviation. To test for Association between sample characteristics and their selfefficacy, Pearson's chi-square test was used but if the distribution cells have a small values, Fisher exact test were the preferred. Test of marginal homogeneity was used to compare changes at self-efficacy and motivation inventory at the different study phases while correlation analysis was used to test for nature (positive/negative) and strength (weak, intermediate or strong) of relation between different domains of self-efficacy and motivation.

\section{Results}

Table (1): Distribution of the Students according to their demographic characteristics $(n=311)$.

\begin{tabular}{|c|c|c|}
\hline Demographic data & No & $\%$ \\
\hline \multicolumn{3}{|l|}{ Gender } \\
\hline - Female & 234 & 75.2 \\
\hline - Male & 77 & 24.8 \\
\hline \multicolumn{3}{|l|}{ Age (years) } \\
\hline - $18-$ & 289 & 92.9 \\
\hline - $22+$ & 22 & 7.1 \\
\hline Mean \pm SD & & \\
\hline \multicolumn{3}{|l|}{ Studying hours at home } \\
\hline - 2 hours & 77 & 24.8 \\
\hline - 4 hours & 166 & 53.4 \\
\hline - 6 hours & 68 & 21.9 \\
\hline
\end{tabular}


Table (2): Distribution of the students Self-efficacy according to pre and post intervention. ( $n=311)$.

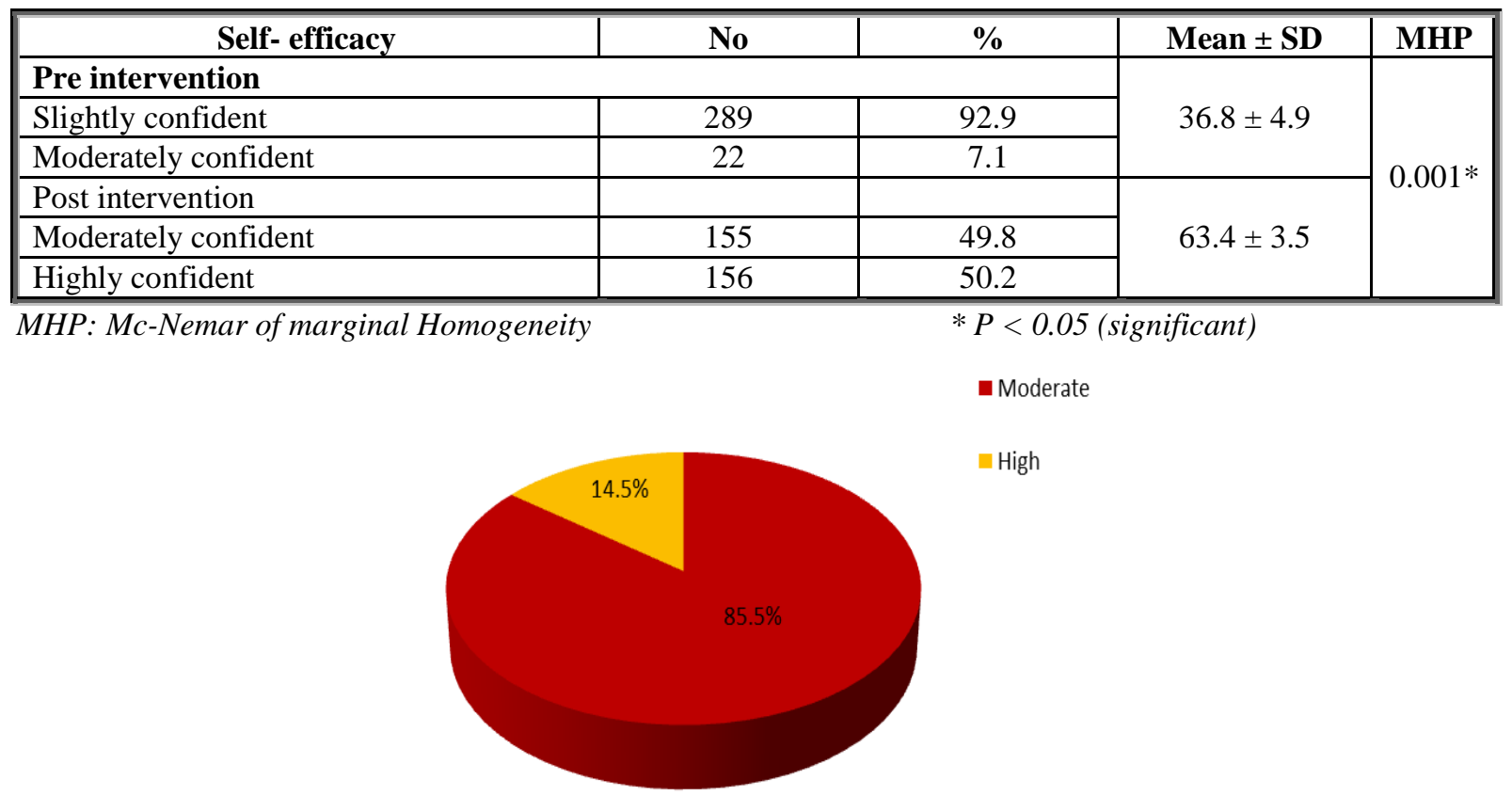

Figure (1): Overall Intrinsic Motivation

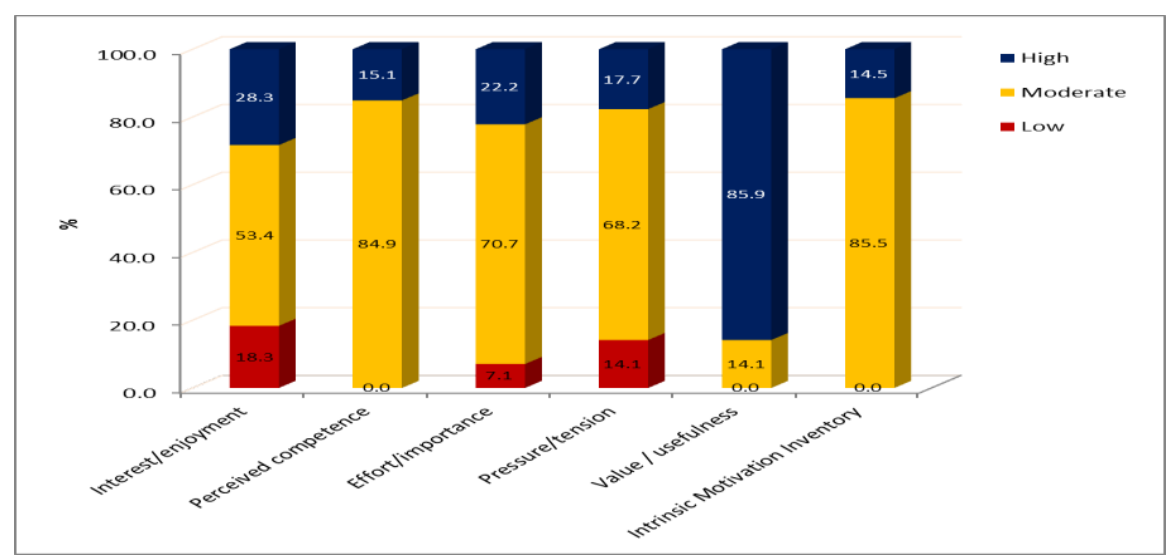

Figure ( 2): Intrinsic Motivation dimensions

Table (3): Distribution of the students according to intrinsic motivation feedback questions. $(n=311)$.

\begin{tabular}{|l|c|c|}
\hline \multicolumn{2}{|c|}{ Intrinsic Motivation feed back } & No \\
\hline Doing intrinsic motivation activities is useful & 179 & 57.6 \\
\hline - Improve communication with patient & 66 & 21.2 \\
\hline Motivate students & 66 & 21.2 \\
\hline Useful for dealing with patient & 198 & 63.7 \\
\hline It is important to do because & 47 & 15.1 \\
\hline - Help in dealing with patient & 66 & 21.2 \\
\hline - Decrease gap between theory and practice & \multicolumn{2}{|l|}{} \\
\hline Dealing with patient problem & 231 & 74.3 \\
\hline Doing intrinsic motivation activities help me to & 58 & 18.6 \\
\hline - Improve skills \& knowledge & 22 & 7.1 \\
\hline - Dollect information about patient & \multicolumn{2}{|l|}{} \\
\hline
\end{tabular}


Table (4): Relationship between self-efficacy and demographic characteristics of the students.(n=311).

\begin{tabular}{|c|c|c|c|c|c|}
\hline \multirow{3}{*}{ Demographic characteristics } & \multicolumn{4}{|c|}{ Self- efficacy pre- intervention } & \multirow{3}{*}{ FEP } \\
\hline & \multicolumn{2}{|c|}{ Slightly confident } & \multicolumn{2}{|c|}{ Moderately confident } & \\
\hline & No & $\%$ & No & $\%$ & \\
\hline \multicolumn{5}{|l|}{ Gender } & \multirow{3}{*}{$0.005 *$} \\
\hline - Female & 212 & 90.6 & 22 & 9.4 & \\
\hline - Male & 77 & 100.0 & 0 & 0.0 & \\
\hline \multicolumn{5}{|l|}{ Age (years) } & \multirow{3}{*}{0.179} \\
\hline - $18-$ & 267 & 92.4 & 22 & 7.6 & \\
\hline - $22-$ & 22 & 100.0 & 0 & 0.0 & \\
\hline \multicolumn{5}{|l|}{ Studying hours at home } & \multirow{4}{*}{$0.003 *$} \\
\hline - 2 hours & 66 & 85.7 & 11 & 14.3 & \\
\hline - 4 hours & 155 & 93.4 & 11 & 6.6 & \\
\hline - 6 hours & 68 & 100.0 & 0 & 0.0 & \\
\hline
\end{tabular}

FEP: $P$ value based on Fisher exact probability

$* P<0.05$ (significant)

Table (5): Relationship between overall intrinsic motivation and demographic characteristics of the students. $(\mathbf{n}=\mathbf{3 1 1})$.

\begin{tabular}{|c|c|c|c|c|c|}
\hline \multirow{3}{*}{ Demographic data } & \multicolumn{4}{|c|}{ Intrinsic Motivation } & \multirow{3}{*}{ FEP } \\
\hline & \multicolumn{2}{|c|}{ Moderate } & \multicolumn{2}{|c|}{ High } & \\
\hline & No & $\%$ & No & $\%$ & \\
\hline \multicolumn{5}{|l|}{ Gender } & \multirow{3}{*}{$0.001 *$} \\
\hline - Female & 211 & 90.2 & 23 & 9.8 & \\
\hline - Male & 55 & 71.4 & 22 & 28.6 & \\
\hline \multicolumn{5}{|l|}{ Age (years) } & \multirow{3}{*}{$0.001 *$} \\
\hline - 18 & 255 & 88.2 & 34 & 11.8 & \\
\hline - $22-$ & 11 & 50.0 & 11 & 50.0 & \\
\hline \multicolumn{5}{|l|}{ Studying hours at home } & \multirow{4}{*}{$0.001^{*}$} \\
\hline - 2 hours & 55 & 71.4 & 22 & 28.6 & \\
\hline - 4 hours & 154 & 92.8 & 12 & 7.2 & \\
\hline - 6 hours & 57 & 83.8 & 11 & 16.2 & \\
\hline
\end{tabular}

Table (6): Correlation matrix between self-efficacy and intrinsic motivation. ( $n=311)$.

\begin{tabular}{|l|c|c|c|c|c|c|c|}
\hline \multicolumn{1}{|c|}{ Item } & $\begin{array}{c}\text { Total Self - } \\
\text { efficacy(post) }\end{array}$ & $\begin{array}{c}\text { Interest/ } \\
\text { Enjoyment }\end{array}$ & $\begin{array}{c}\text { Perceived } \\
\text { competence }\end{array}$ & $\begin{array}{c}\text { Effort/ } \\
\text { Importance }\end{array}$ & $\begin{array}{c}\text { Pressure } \\
\text { /tension }\end{array}$ & $\begin{array}{c}\text { Value / } \\
\text { usefulness }\end{array}$ & $\begin{array}{c}\text { Total } \\
\text { intrinsic } \\
\text { motivation }\end{array}$ \\
\hline Total Self -efficacy(post) & 1 & & & & & & \\
\hline Interest/enjoyment & $0.43^{*}$ & 1 & & & & & \\
\hline Perceived competence & -0.08 & 0.01 & 1 & & & & \\
\hline Effort/importance & $0.13^{*}$ & 0.00 & $-0.27^{*}$ & 1 & & & \\
\hline Pressure/tension & $-0.14^{*}$ & -0.06 & -0.06 & $-0.17^{*}$ & 1 & & \\
\hline Value / usefulness & -0.08 & $0.12^{*}$ & 0.00 & $0.21^{*}$ & -0.08 & 1 & \\
\hline Total Intrinsic Motivation & $0.11^{*}$ & $0.48^{*}$ & 0.10 & $0.29^{*}$ & $0.63^{*}$ & $0.39^{*}$ & 1 \\
\hline
\end{tabular}

*: significant correlation coefficient

Interpretation of correlation co-efficient

Weak (0.1-0.24) Intermediate (0.25-0.74) Strong (0.75-0.99) 
Table (1): Revealed that the highest percentage of the first year students were females $(75.2 \%)$; where as $24.8 \%$ were males. Their age ranged from 18: 22 years old with means and standard division $(19.0 \pm$ 1.0). More than half of them were studying four hours, a quarter were studying two hours and the $21.9 \%$ six hours.

Table (2): Distribution of the students according to pre and post self- efficacy. It could be observed from the table that, $92.9 \%$ of the students were slightly confident, while only $7.1 \%$ of them were moderately confident in pre intervention. Expectedly, after intervention the results increased significantly as half of them became moderately confident and the other half became highly confident. $(\mathrm{P}=0.001)$

Figure (1): Explained, that, $85.5 \%$ of the students got moderate score of intrinsic motivation, while, $14.5 \%$ got high scores post intervention. However, no one got low scores.

Figure (2): Illustrate that the highest dimension of intrinsic motivation was value / usefulness dimension $(85.9 \%)$, followed by interest/ enjoyment dimension (28.3\%), and effort / importance dimension (22.2\%) respectively. While the least dimensions were: pressure/ tension and perceived competence $(17.7 \%$, $15.1 \%$ ) respectively.

Table (3): Showed that more than half of the students stated that:" simulation help us improving communication with the patient", $63.7 \%$ of them answered that simulation help in dealing with the patient and nearly three quarters of them mentioned that simulation improve skills and knowledge than other traditional methods.

Table (4): Mentioned the relationship between selfefficacy (pre-intervention) and demographic characteristics of the students. Statistically significantly difference was found between (pre) selfefficacy and gender and studying hours $(\mathrm{P}=0.005$, 0.003), respectively. However, there was not statistically significantly difference with age $\quad(\mathrm{P}=$ 0.179) It was found that females were more confident (higher self-efficacy) than males when practicing simulation in the medical surgical department $(9.4 \%$, $0.0 \%$ ) respectively. Students who were moderately confident studied from two to four hours at home.

Table (5): Demonstrated the relationship between the overall intrinsic motivation and students' demographic characteristics; it was found that male students were more competent than female' students. Besides that competency was higher for students who studied two hours only (28.6\%). Statistically significantly difference was found between the overall intrinsic motivation and students' gender, age and studying hours. $(\mathrm{P}=0.001)$

Table (6): Shows correlation matrix between total self-efficacy and intrinsic motivation subscales as it was found that, a significant positive weak correlation between total self- efficacy and total intrinsic motivation and a significant positive intermediate correlation between total score of selfefficacy and interest/ enjoyment subscale. The same correlation was found between total intrinsic motivation and pressure/tension as well as value/usefulness.

\section{Discussion}

Nursing education program prepares students to be safe, effective, and efficient professionals in nursing practice. One solution is to use simulation, in order to replicate some of the essential aspects of a clinical situation, so it may be readily understood and managed when it occurs in reality Foronda, Liu, \& Bauman, (2013). Simulation is a well-researched, effective method to teach nursing that can be adapted to teach students. It does not have to be hightechnology, high-fidelity or expensive to be a positive learning experience for students (Foronda , Liu, \& Bauman, 2013). For these reasons, this study aimed to assess the effect of simulation as a learning approach on self-efficacy and intrinsic motivation of the first year medical surgical nursing student in Damanhour University (Egypt).

In this study, it is proved that there is an effect of simulation on the students' self -efficacy and intrinsic motivation. The results of the current study revealed that the majority of the students were slightly confident before conducting the simulation sessions: on the other hand, after simulation, the confidence level increased significantly, as students, were splinted into two halves approximately, (highly and moderately confident) when practicing the nursing procedures; whereas no one was slightly confident. This result emphasizes the value of simulation to nursing students, who felt more confident after practicing simulation (role play, case study, problem solving, demonstration, re-demonstration as in practicing bed making, IM leg injection "device leg shows sites of injection" and IV arm "device arm contains veins"). Some students mentioned that they prefer learning by doing. Many studies support this finding and indicated that simulation in nursing education is useful in creating a positive learning environment that contributes to an increase in selfconfidence, with learning and self-efficacy (Rothgeb, 2008, Van Heukelom, Begaz, \& Treat, 2010, Tosterud, 2014).

This is in line with Rothgeb, (2008), who found that simulations are safe and efficient teaching strategies that mimic the reality of the clinical nursing environment; and enhance positive learning environment, such as interactive videos and 
mannequins; simulations demonstrate relevant nursing procedures and train nurses in critical decision-making. Furthermore, Shinnick, (2011) indicated a statistically significant difference in selfconfidence after applying low-fidelity simulation.

In addition to that, Frank, Coke \& Suling, (2009) stated that the simulation of clinical experience by the students showed an increase in their self-confidence while caring for patients in real situation. Moreover \& Martin (2012), conducted a study in Portugal and Brazil, mentioned that a significant improvement in expertise and students' practical competences compared to traditional teaching methods; besides self-efficacy and self-confidence in assessing vital signs and offering patient education; as well as skills development to solve problems, to think and act as nurses and to develop communication competences. Additionally, Smith \& Roehrs (2009) determined that $94 \%$ of the students felt confident in their ability to care for patients with respiratory issue after participation in the simulation.

Moreover, studies conducted by Gordon \& Buckley (2009), Bruce, Scherer, Curran, Urschel, Erdley, \& Ball, (2009) demonstrated statistically significant improvements in knowledge and confidence. It also found that, after simulation, nursing students reported increased confidence in their ability to perform both technical and nontechnical aspects of responding to patient clinical emergencies.

On the other hand, many studies compared achieved traditional lectures versus simulation-based learning to achieve self-confidence, and revealed that the students preferred the familiar and traditional methods than simulation (Rothgeb, 2008, Schlairet, 2011, Foronda, Liu, \& Bauman, 2013, Tosterud, 2014) added that students, who had progressed in their studies, reported a lower degree of selfconfidence with simulation based learning. Furthermore, Parker, McNeill, Pelayo, Goei, Howard, \& Gunter, (2011) found no significant gains in confidence after the simulation experience. Bremner , Aduddell , Bennett, \& Van Geest, (2006) also, studied the effect of simulation on first year nursing students' cognitive skills and confidence levels, and demonstrated no statistically significant differences between groups in respect to students' perceived confidence levels. Finally, Massias, study (2009), compared the effect of simulation with traditional clinical learning experiences, revealed that no differences were found in students' pre- and posttest performance and confidence; and that both simulation and traditional clinical experience were equally as effective in fostering the cultivation and refinement of critical thinking skills among nursing students.
In Egypt, Soliman, sheble , Shrief, (2014), study in El Mansoura University revealed that, there is no difference in level of confidence between two groups of students (experimental \& control), due to limited period of exposure to simulation training.

Regarding intrinsic motivation, the findings of the this study revealed that the majority of the nursing students got moderate score, and $14.5 \%$ got high scores intrinsic motivation post -simulation intervention. This is in accordance with Gleek (2014) who concluded that, a students' participation in classroom simulations correspond positively with student engagement, motivation, and learning. This is supported by Ariely (2013), who stated that an individual's motivation is the sum of payment, meaning, creation, challenge, ownership, pride, and identity. Moreover, the simulation-based education had a greater degree of motivation and students were found to be intrinsically motivated to participate in simulations where the goals of those activities are interconnected to the learning outcomes (Ravert, 2004).

Furthermore, Rockstraw (2006)found that selfefficacy and motivation, to initially attempt and master a skill, are essential variables in a successful nursing education and using simulation, for skill acquisition prior to nursing student clinical rotations, increased student self-efficacy and motivation, which in turn, strengthen the belief that they have control of their learning environment. Learning in a simulation environment, which allows for errors while protecting the patient, gives the learner a real world practice setting that should improve confidence and motivation and reduce errors ( Zulkosky, 2012).

Pertaining to the relationship between self- efficacy and demographic characteristics of the medicalsurgical nursing students, there were statistical significant differences between self-efficacy and both gender and studying hours at home; while no statistical significant difference was found with age, as all students had the same age. Female nursing students were more confident than males when practicing simulation; whereas males are more competent and more internally motivated than females. This result may be attributed to the students, who lives in rural communities and where gender discrimination is present, because family support and encourage boys than girls; as well as male nursing students do the practice with more competency because of their work in private hospitals. Students, who got moderate score in confidence, were studying from two to four hours. This may be due to the increase in studying hours give students a good base, which consequently lead to be more self- confident in their knowledge. 
This is in line with, several studies, which suggested that gender is an especially powerful predictor of a student's ability to acquire spatial information from simulation (Kameg, Howard, Clochesy, Mitchell, \& Suresky, 2010, Nishisaki, Donoghue, Colborn, Watson, Meyer, Brown, Nadkarni M.,2010; Zulkosky, 2012). This is partially congruent with Hall (2013), who revealed that gender, and age did not contribute to simulation because women were found to be less accurate than men due to bearing estimations their liability to be trained in a way that eliminates or reduces gender differences; thus, the findings concluded that simulation had improved nursing students' confidence that served to motivate them.

Concerning the relationship between the overall intrinsic motivation and medical surgical nursing students' demographic characteristics, the findings revealed that male students were more competent than female students. Besides that, the competency was higher for students who studied only two hours only. Moreover, Statistical significant differences were found between the total intrinsic motivation and students' gender, age and studying hours. This is consistent with the results of a study that reported a raise in motivation level of female college students, than males after simulation (Zulkosky, 2012).

Contradictory, Alininier, (2006) claimed that positive feedback increased intrinsic motivation among male nursing students; whereas it decreased intrinsic motivation among females; as well as female had slightly higher levels of self-determination and less motivation than male. Moreover, Caison, Bulman, Pai, \& Neville, (2008), found that male had higher innovativeness scores than female and increasing age is negatively correlated with optimism and innovativeness. Tlauka, Brolese, Pomeroy, Hobbs W. 's study (2005) also found, in their study, that age was positively associated with motivation to learn and impacted on both motivations to learn and transfer of training; as expertise and age are predictors of motivation, and found a statistical significant difference between age and motivation.

Regarding relationship between self-efficacy and intrinsic motivation subscale, it was found that there was a significant positive weak correlation between total self- efficacy and total intrinsic motivation. Furthermore, significant positive intermediate correlations between self-efficacy and interest/ enjoyment subscale, and the same correlation was found between pressure and tension; value/usefulness and total intrinsic motivation. This is partially in line with Ashraf (2011) whose study, showed significant differences between competence subscales of the intrinsic motivation; and that students who were given the virtual clinical excursion experience scored lower on competence subscales than students exposed to the human patient simulation, as these indicated that they had more freedom in choosing to complete the exercise than did those students in the virtual clinical excursion experience. Concerning value/usefulness subscale of intrinsic motivation, Ashraf, (2011) study, revealed that students, who experienced the human patient simulation got significantly higher scores on the value/usefulness subscale; as well as average group score than those who experienced the virtual clinical excursion simulation setting. This is in accordance with Wagner, Bear, \& Sander, (2009), who found that students with high motivation provided more written comments and had often associated stimulating content and instructors with positive attitude and the desire to be a nurse as motivational factors. Consistency, Ashraf's findings (2011), found statistical significant difference among intrinsic motivation dimensions \& found a significant positive influence on intrinsic motivation for academic learning.

Regarding medical surgical students ' feedback on the simulation experience, students mentioned that " simulation help us improving communication with the patient", $63.7 \%$ of them answered that simulation help in dealing with the patient and nearly three quarters of them mentioned that simulation improve our skills and knowledge than the traditional methods. Others mentioned "it decrease the gap between theory and practice", while others stated that "it decreases the fear of making mistakes before practicing on the patients. In Sharif \& Masoumi, (2005) study indicated that the initial clinical experience was the most anxiety producing part of their clinical experience. The clinical instructor can play an important role in student nurses' selfconfidence and encourage independence which leads to clinical competency (Jensen, Eldridge, Hu \& Tuten, 2010).

Finally, Simulation was found to be an acceptable learning strategy for novice nursing students and help create a positive learning environment and contribute to self-confidence and motivation. Nevertheless, the students need help and support from the educators to be conscious of their learning zone and to be more self -efficacy and motivated (Jensen, Eldridge, Hu \& Tuten, 2010).

\section{Conclusions}

Results of this study showed that there was a significant difference in the students' self - efficacy and intrinsic motivation after using simulation. Students in faculty of Damanhour University as valuable teaching strategy that promotes active 
learning, clinical competence, and improved selfconfidence.

\section{Recommendations}

In the light of the findings of this study, the faculty /nurse educators should:

- Encourage using various forms of simulation when appropriate with all students; as well as evidence - based practice before teaching any nursing skill in order to provide the best quality updated learning for students.

- Conduct educational workshops for all clinical nurse educators to increase their competencies in using simulation.

- Faculty staff should evaluate student feedback regarding different teaching methods especially in clinical practice.

- Provide nursing students with activities that increase their perceived confidence and competence levels as simulation.

- Further studies can be conducted with other academic years of nursing students to attain generalizability of the findings.

\section{References}

1. Alinier G., Hunt B., Gordon R., \& Harwood C., (2006): Effectiveness of intermediate fidelity simulation training technology in undergraduate nursing education. Journal of Advanced Nursing, 54(3), 359-369.

2. Ariely D., (2013): What makes us feel good about our work? [Video]. Retrieved from http://on.ted.com/Ariely

3. Ashrf M., (2011): Achievement Goals and Intrinsic Motivation: A Case of IIUM. International Journal of Humanities and Social Science, 1 (6); 197-199.

4. Bandura, (2006): Guide for constructing selfefficacy scales. In F. Pajares \& T Urdan (Eds.), Self-efficacy beliefs of adolescents, p. 307-337. Greenwich, CT: Information Age.

5. Bandura A., (1977): Self-efficacy: Toward a unifying theory of behavioral change. Psychological Review, 84(2), 191-21.

6. Bremner M., Aduddell K., Bennett D., \& Van Geest J., (2006): The use of human patient simulators: Best practices with novice nursing students. Nurse Educator, 31(4), 170-174.

7. Bruce S., Scherer Y., Curran C., Urschel D., Erdley S., \& Ball L., (2009): A collaborative exercise between graduate and undergraduate nursing students using a computer-assisted simulator in a mock cardiac arrest. Nursing Education Perspectives, 30(1), 22-27.
8. Cant R., \& Cooper S., (2010): Simulationbased learning in nurse education: systematic review. Journal of Advanced Nursing, 66(1), 315.

9. Caison A., Bulman D., Pai S., \& Neville D., (2008): Exploring the technology readiness of nursing and medical students at a Canadian university. Journal of Inter-professional Care, 22(3), 283-294.

10. Foronda C., Liu S., \& Bauman E., (2013): Evaluation of Simulation in Undergraduate Nurse Education: An Integrative Review. Clinical Simulation in Nursing, 9(10), 409-416.

11. Frank D., Coke L., Suling L., (2009): The Effect of High-Fidelity Simulation on Nursing Students' Knowledge and Performance: A Pilot Study. National Council of State Boards of Nursing, Inc. USA, 40(1)10-15.

12. Gleek C., (2014): Understanding Student Engagement during Simulations. Lynn University (PHD thesis) USA, 54-66.

13. Gagne M., \& Deci E., (2005): Selfdetermination theory and work motivation. Journal of Organizational Behavior, 10(5), 331362.

14. Gordon C., Buckley T., (2009): The effect of high-fidelity simulation training on medicalsurgical graduate nurses' perceived ability to respond to patient clinical emergencies; J Cout inEdcNurs; 40(11):491-8.

15. Hall R., (2013). Effects of High Fidelity Simulation on Knowledge Acquisition, SelfConfidence, and Satisfaction with Baccalaureate Nursing Students Using the Solomon-Four Research Design. (PHD thesis), East Tennessee State University USA, 60-75.

16. Intrinsic motivation inventory. SelfDetermination Theory: Questionnaires. Retrieved on 17th December, (2007): available from:

http://www.psych.rochester.edu/SDT/measures/i ntrins_scl.html

17. Jeffries P., (2005): A framework for designing, implementing, and evaluating simulations used as teaching strategies in nursing. Nursing Education Perspectives, 26(2), 96-103.

18. Jeffries P., Rodgers K., (2007b): Theoretical framework for simulation design. In P. Jeffries (Ed.), Simulation in nursing education: From conceptualization to evaluation (pp. 21-33.). New York: National League for Nursing.

19. Jensen D., Eldridge D., Hu \& Tuten J., (2010): Teaching and learning in the comfort zone: A guide for new teachers and literacy coaches. New York: Palgrave Macmillan. 
20. Kameg K., Howard V., Clochesy J., Mitchell A., \& Suresky J., (2010): The Impact of High Fidelity Human Simulation on Self-Efficacy of Communication Skills. Issues in Mental Health Nursing, 31(5), 315-323.

21. Leigh G., (2008): Examining the relationship between participation in simulation and the levels of self-efficacy reported by nursing students. (PHD thesis) USA, Dissertations Abstracts International, 68(11).

22. Martins M., (2012): The simulated clinical experience in nursing education: a historical review Portugal and Brazil Acta Paul Enferm. 25(4):619-25.

23. Massias L., (2009): Influencing critical thinking in nursing education: Comparing high-fidelity simulations and traditional clinical training, USA, (PHD thesis),60-66. Retrieved from ProQuest Dissertations and Theses. (AAT 3370941)

24. Mohsen M., Okby O., Reiad N., Fareed M., El Sheikh A., (2011): Virtual Reality Lab; innovative methods in Nursing Skill Laboratory Health and Medicine technology, Menofia University Egypt.

25. National League for Nursing. Nursing data review (2007-2008) Baccalaureate, associate degree, \& diploma programs. (2010): Available at http://www.nln.org/research/slides/ndr)0708.pdf

26. Nishisaki A., Donoghue A., Colborn S., Watson C., Meyer A., Brown C., Nadkarni M., (2010): Effect of just-in-time simulation training on tracheal intubation procedures safety in the pediatric intensive care unit. Anesthesiology, 113(1), 214-223.

27. Norman J., (2012): Systematic review of the literature on simulation in nursing education. ABNF Journal, 23(2), 24 - 28.

28. Paige J., (2013): Simulation Design Characteristics: Perspectives Held by Nurse Educators and Nursing Students, University of Wisconsin-Milwaukee Follow PHD, USA, P367.

29. Parker R., McNeill J., Pelayo L., GoeiK., Howard J., \& Gunter M., (2011): Pediatric clinical simulation: A pilot project. Journal of Nursing Education, 50(2), 105-111.

30. Ravert P., (2004): Use of a human patient simulator with undergraduate nursing students: A prototype evaluation of critical thinking and selfefficacy. Unpublished PHD dissertation, University of Utah, Utah, USA, 60-72.

31. Ryan R., Mims V., \& Koestner R., (1983): Relation of reward contingency and interpersonal context to intrinsic motivation: A review and test using cognitive evaluation theory. Journal of Personality and Social Psychology, 45, 736-750.

32. Rystedt H., Lindström B., (2001): Introducing simulation technologies in nurse education: a nursing practice perspective. Nurse Education in Practice, 1:134-141.

33. Rockstraw J., (2006): Self-efficacy, locus of control and the use of simulation in undergraduate nursing skills acquisition. (PHD thesis) Dissertation Abstracts International, USA, 45-55.

34. Rothgeb M., (2008): Creating a nursing simulation laboratory: A literature review. Thorofare, 47(11), 489-94.

35. Smith M., (2009). Creative clinical solutions: Aligning simulation with authentic clinical experiences. Nursing Education Perspectives, 30(2), 126-128.

36. Smith S., \& Roehrs C., (2009): High-fidelity simulation: Factors correlated with nursing student satisfaction and self-confidence. Nursing Education Perspectives, 30(2), 74-78.

37. Schlairet M., (2011): Simulation in an Undergraduate Nursing Curriculum: Implementation and Impact Evaluation. Journal of Nursing Education, 50(10), 561-568.

38. Schwarzer R., \& Scholz U., (2000): Crosscultural assessment of coping resources: The General Perceived Self-Efficacy Scale. Paper presented at the First Asian Congress of Health Psychology: Health Psychology and Culture, Tokyo, Japan.

39. Sharif F., Masoumi S., (2005). A qualitative study of nursing student experiences of clinical practice BMC Nurs; 4: 6 .

40. Shinnick M., (2011): Debriefing: The Most Important Component in Simulation? Clinical simulation in Nursing, 7 (3); e105-e111.

41. Soliman H., sheble A., Shrief W., (2014): Effectiveness of Simulation training on clinical Nursing Education and competence: Randomized Controlled Trial .International Journal of Advanced Research, 2(4), 387-393.

42. Tlauka M., Brolese A., Pomeroy D., Hobbs W., (2005): Gender differences in spatial knowledge acquired through simulated exploration of a virtual shopping center. Journal of Environmental Psychology, (25) 1; 111-118.

43. Tosterud R., (2014): Simulation used as a learning approach in nursing education Students' experiences \& validation of evaluation questionnaires. Gjovik University College WWW.KAU.SE

44. Van Heukelom N., Begaz T., \& Treat R., (2010): Comparison of post-simulation debriefing versus in-simulation debriefing in 
medical simulation. Simulation in Healthcare, 5(2), 91-97.

45. Wagner D., Bear M., \& Sander J., (2009): Turning simulation into reality: Increasing student competence and confidence. Educational Innovations, 48(8), 465-467.

46. Ward-Smith P., (2008): The effect of simulation learning as a quality initiative. Urologic Nursing, 28(6), 471-473.

47. World Health Organization (WHO) (2011): Patient safety curriculum guides: Multiprofessional edition. Retrieved 21.03.2014, from http://whqlibdoc.who.int/publications/2011/9789 241501958_eng.pdf4- WHO.

48. Yuan H., Williams B., Fang J., \& Ye Q., (2012): A systematic review of selected evidence on improving knowledge and skills through high-fidelity simulation. Nurse Education Today, 32(3), 294-298.

49. Zulkosky K., (2012): Simulation Use in the Classroom: Impact on Knowledge Acquisition, Satisfaction, and Self-Confidence. Clinical Simulation in Nursing, 8(1), 25-33. 